\title{
Fiscal policy and its implication for central banks
}

\author{
Suchada Kirakul ${ }^{1}$
}

\begin{abstract}
Over the past decade, prudent fiscal management has served Thailand well in cushioning the impact of the global financial turbulence. However, going forward, fiscal risks which include a weakened global economic outlook, unbalanced fiscal structure and growing contingent liabilities may have implications for fiscal debt sustainability in the medium term. Since the credibility of fiscal policy greatly influences the conduct and effectiveness of monetary policy, central banks have an incentive to monitor fiscal positions closely. At the same time, it is important to preserve central bank independence and credibility to ensure that the central bank can carry out its primary mandate. In relation to this, policy coordination between the central bank and the government is crucial both in terms of policy stance and public debt management, which will also help foster bond market development and promote financial stability.
\end{abstract}

Keywords: Thailand public debt, fiscal and monetary policy, fiscal risk

JEL classification: E52 E61 E62 H63

\footnotetext{
1 Bank of Thailand.
} 


\section{Introduction}

The credibility of fiscal policy greatly influences the conduct and effectiveness of monetary policy. Monetary policy is more effective when the private sector trusts that the government will not resort to inflationary deficit financing. Therefore, central banks have an incentive to monitor fiscal positions closely as: (1) the governments may be tempted to call on central banks for debt financing, which would then directly damage the central bank's credibility; and (2) fiscal policy can have a significant impact on the economy as well as the financial markets.

Analysis of fiscal policy and public debt sustainability often hinges on the expected path of public debt. Underlying the projected debt dynamics are factors such as the ability of the government to raise revenues or limit expenditures, medium-term growth prospects and market sentiment that may influence the cost and availability of financing. Rising contingent liabilities, especially those that are less transparent and implicit in nature, may result in a surprise public debt overshoot. The next section of this country paper will offer a brief review of Thailand's public debt development. The paper will then highlight a number of concerns regarding fiscal policy and public debt, followed by important implications for the central bank.

\section{Country experience: Thailand}

\subsection{Development of the fiscal position and public debt}

Over the past 25 years, Thailand's public debt path has reflected prudent fiscal management overall - never exceeding the fiscal sustainability guideline of 60 percent of GDP even during the 1997 Asian crisis. Below is a short discussion of two notable episodes in the evolution of Thailand's public debt.

\section{The pre- and post-Asian crisis: 1990 to 2007}

As depicted by Figure 1, the public debt-to-GDP ratio was on a declining trend from 1990 up to the onset of the Asian crisis, bottoming out at 13.5 percent of GDP in 1996 after nine consecutive years of fiscal surpluses. Then, during 1997-2000, there was a sharp rise in public debt to a peak of 57.8 percent of GDP in 2000, as a result of the financial sector bailout during the crisis and the countercyclical role of the public sector to restore the economy $^{2}$. Efforts to reduce the public debt level to achieve fiscal consolidation then followed, and when coupled with the strengthening economy, led to a continuous decline in ratio of public debt to GDP until 2007.

2 It should be noted that the total amount of public debt already incorporates the outstanding debt of the Financial Institutions Development Fund (FIDF). 


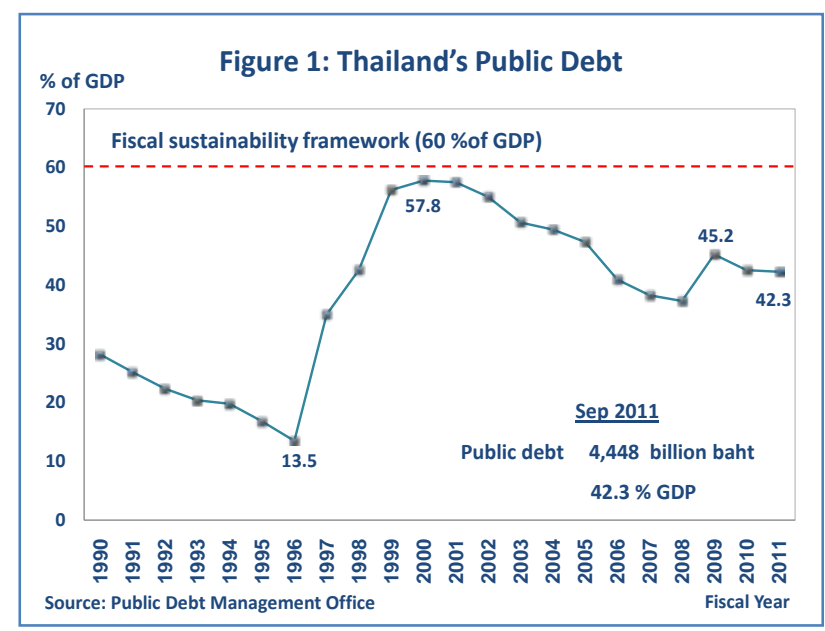

\section{Cushioning the impact of the global financial crisis: 2007 onwards}

As in many countries, the global financial crisis necessitated a fiscal expansion in Thailand. Besides running sizable budget deficits during the past five fiscal years (FY2007-2011), the government also engaged itself in borrowing to mobilize funds for additional investment projects under the "Strong Thailand" project (FY2009-2012), totaling around 3.5 percent of GDP. Moreover, with many upcoming government initiatives to maintain the incumbent government's popularity, coupled with extraordinary spending to mitigate the negative impact of the recent flood disaster (e.g. urgent relief expenses to assist adversely affected people, spending to restore confidence, and the medium- and long-term investment projects in water management system infrastructure of preliminarily around 3.5 percent of GDP), the government's expenditure is likely to expand substantially in the periods ahead. Though these efforts have been vital to counter a deep and long recession and propel the economy forward, the fiscal consolidation plan will inevitably be delayed.

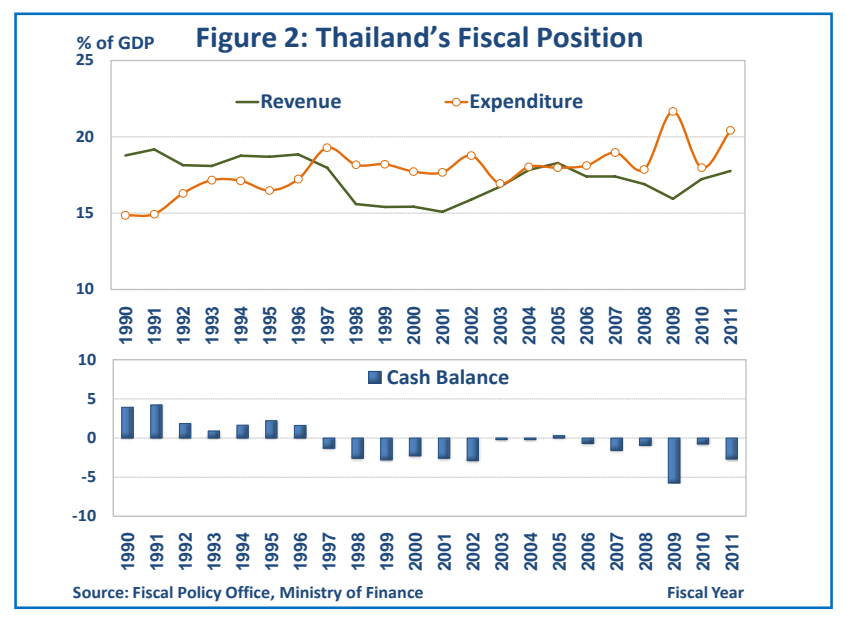

At present, the current public debt level is roughly 40 percent of GDP - this figure already incorporates the FIDF debt totaling 1.14 trillion baht at the end of 2011 . This level is considered manageable and has some room for fiscal deficit; however, the debt level will likely continue rising in the medium term. Should the global economy be weaker than expected, fiscal consolidation could be further delayed and the debt-to-GDP figures could be even higher and closer to the threshold. There are also a few concerns regarding fiscal risks in the medium term, as discussed in the next sub-section. 
1. The weakened global economic outlook will likely weigh on domestic growth prospects, implying the possibility of a greater need for fiscal stimulus in the periods ahead. While fiscal stimulus can be quite effective in smoothing economic cycles, caution must be exercised in ensuring not to over-stretch the fiscal room. In particular, as we head into a period of heightened uncertainties, some insurance, i.e. retaining some fiscal buffers for emergency, may be needed, though this seems difficult to achieve given politicians' short policy horizon. The key to lessening this risk is to better align the length of the policy horizons of politicians and institutions charged with the economic and financial stability mandate.

2. The unbalanced fiscal structure may limit fiscal room, resulting in greater reliance on debt financing and declining debt service ability. Currently, Thailand's fiscal structure is unbalanced in two ways. First, expenditures have been growing on average twice as fast as revenues during the past five years, owing to a rapid increase in expenditures associated with social welfare and education, and the continued expansion of government initiatives. On the other hand, revenue collection, averaging about 17 percent of GDP, is modest compared to other emerging countries, owing to a narrow tax base and numerous tax exemptions and deductions. Second, the expenditure side is fairly skewed towards current spending. During the past 10 years, capital expenditure has declined from 24 percent to 17 percent of total budget in 2011. Taking into account infrastructural investment through Public-Private Partnerships (PPPs), the amount is still low. The low public investment is a concern in terms of the country's medium-term growth potential that will come back to affect revenue collection, increase the budget deficit, and further fuel the uptrend in public debt. Furthermore, with GDP growing at a slower pace while public debt continues to rise, the debt-to-GDP ratio may edge up further and risk becoming unsustainable in the medium term. To address the problem of an unbalanced fiscal structure, there is a need to implement fiscal reforms, especially tax reform and current expenditure cut-back with a view to ensuring fiscal sustainability.

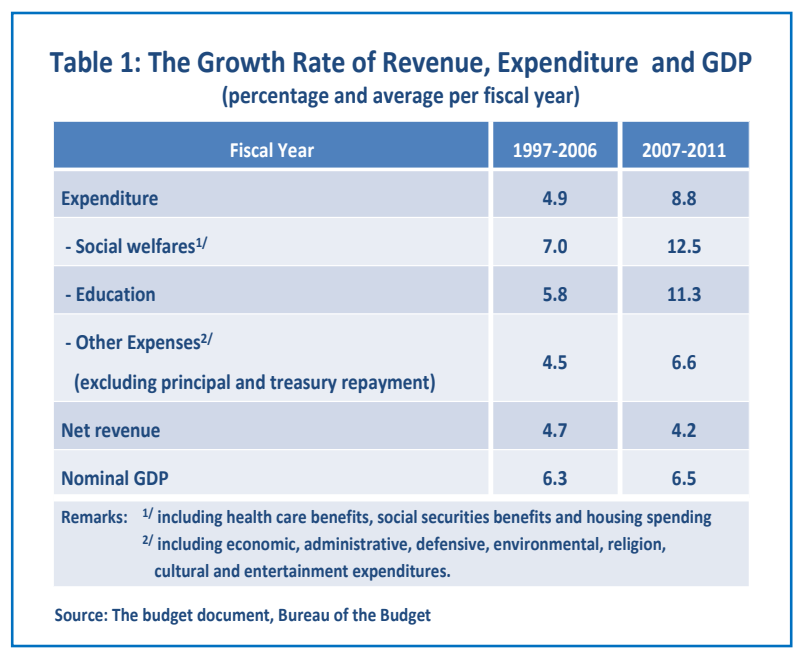

3. Growing contingent liabilities may reduce balance sheet transparency and increase the possibility of a debt surprise that could be particularly negative for the financial markets and financing costs of the government. While explicit government guarantees are already included as part of public debt, the number of government initiatives implemented through government/state owned institutions, for example Specialized Financial Institutions, has increased in recent years. Though 
these activities do not instantaneously create liabilities for the government, in the event that a systemic risk concern arises from significant losses from such activities, the government will be called upon to rescue the institutions in order to maintain confidence. From this perspective, this represents an implicit contingent liability for the government, and efforts should be made to evaluate its fiscal burden. There are several ways to reduce this risk, including (1) bringing such government initiatives on balance sheet; and (2) putting in place a mechanism to ensure effective risk management of the institutions concerned. There is also a risk of creating market distortions. While there are reasons to support the government's role in addressing market failures, care must be taken to not introduce market inefficiencies, for example favorable treatment for certain segments, distorted pricing, and monopoly. To reduce this risk, it is important to strategize the method and timing of exit policies of some government initiatives, involving the private sector as appropriate.

Taken together, these fiscal risks may have important implications for Thailand's fiscal debt sustainability in the medium term, thus deserving serious attention. Moreover, growth in public debt will also imply a higher financing burden, which during an economic expansion may lead to the crowding out of private sector access to sources of funds, inhibiting private sector activities. In addition, with higher indebtedness, the sovereign credit rating may be affected, resulting in a higher cost of financing. The bottom line is that fiscal adjustments will still be required in Thailand to mitigate risks from the global economy and to raise the country's growth potential. At the same time, efforts must be made to ensure that any stimulus measures are based on longer-term economic stability considerations with a view to limiting the risk of fiscal dominance in monetary policy, which is addressed in the final part of this paper.

\section{Implications of fiscal risk for the central bank and challenges ahead}

The fiscal risks highlighted in section 2 and their impact on public debt sustainability will likely have implications for the central bank in the following ways.

1. Closer coordination between the central bank and the Ministry of Finance on fiscal and monetary policies is essential. The recent European debt crisis has underscored the multifaceted nature of the interrelations between fiscal policy, monetary policy and overall financial stability. Though Thailand's fiscal position is still strong and the country is nowhere near on the verge of a debt crisis, addressing this institutional arrangement issue early on is worthwhile. As the main public institutions responsible for the country's macroeconomic policy, coordination between the central bank and Ministry of Finance is therefore crucial. Information sharing, cooperation and coordination between the two institutions need to be ensured in order to put in place sound and coherent macroeconomic policy as well as to better align the length of the policy horizons of the government and the central bank so that everyone is on the same page regarding the country's long-term prospects and risks. In Thailand, the country's main economic institutions meet yearly to discuss the appropriate government budget framework for each fiscal year. The discussion focuses on the outlook for economic and monetary conditions, revenue collection, issuance of government bonds and the sustainable level of public debt, to name but a few. The challenge, however, remains in finding ways to further strengthen and improve this coordination mechanism to ensure greater effectiveness and further stimulate open and candid policy discussions.

2. All non-standard measures taken by the central bank must be restricted to extraordinary circumstances and be temporary, with a clear exit strategy. This is to ensure that the central bank can carry out its primary mandate of price stability. 
It has often been the case that emerging economy central banks are required to take on a number of development functions, pursuing "quasi-fiscal operations" such as extending credit to priority industries, e.g. a coordination mechanism between the central bank and banks to extend credit - soft loans - to flood-affected SMEs. Such practice entails a risk of impairing monetary policy effectiveness, i.e. interest rate pass-through, while the problem of market failures (both credit access and availability) prevail. In this case, the central bank needs to closely gauge the impact of such activities on the money market and conduct appropriate monetary operations - a costly action, but nevertheless important to ensure that monetary policy transmission is not impaired. An additional challenge is how to eventually phase out this role, despite public expectations and political pressure. The exit plan should be well thought through and clearly spelled out.

When economic and financial development takes hold, the central bank needs to return to more normal modes of operation, minimizing the fiscal implications of monetary policy operation, in order to achieve the medium-term goal of price stability. While this challenge may be more easily addressed in advanced economies due to greater clarity in terms of the institutional setup which allows a clear exit strategy and loss bearing responsibilities to be devised, developing economies may face a more difficult time due to the likelihood of greater fiscal dominance on the central bank's operations. Thus, preserving central bank independence and credibility is all the more important at times like this.

3. Political pressures on the central bank to monetize the deficit may intensify. This would complicate the work of the central bank and damage its credibility, which would ultimately undermine the achievement of its primary objective of price stability.

4. The roles of public debt management and central bank bond issuance in fostering bond market development and promoting financial stability

4.1 The government and the Bank of Thailand have made continuous efforts to strengthen and deepen the domestic bond market to create a more resilient financial sector

1. The local bond market has grown by more than double over the past decade. Financial disintermediation since the 1997 crisis has highlighted the importance of financial markets as viable alternative sources of funds to bank loans. The domestic bond market has doubled in size from 33.2 percent of GDP in 2000 to 68.9 percent of GDP in 2010, while the equity market has more than tripled from 26.0 percent of GDP to 82.5 percent of GDP. On the other hand, bank loans have declined from 93.2 to 85.0 percent of GDP. 


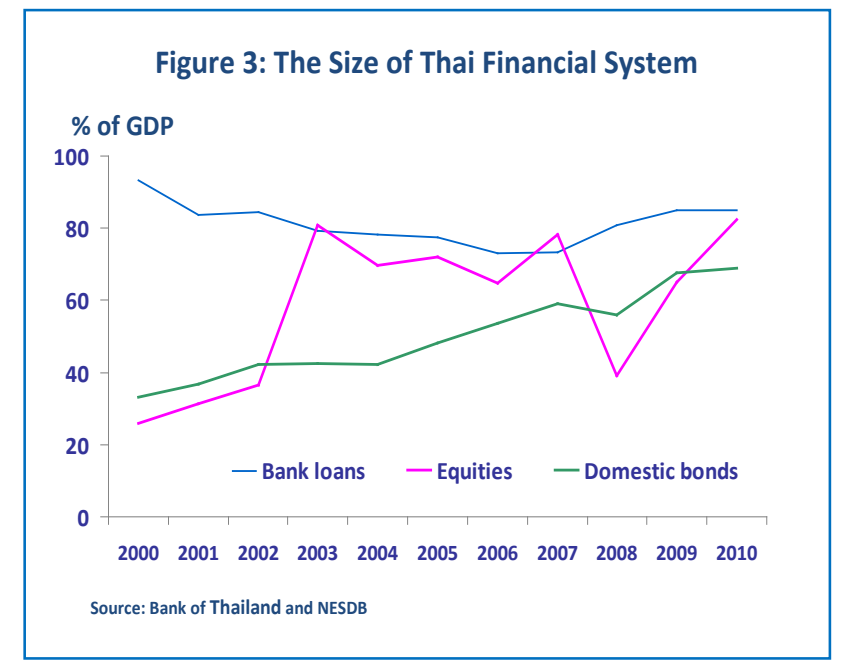

2. The increasing role of domestic bond market as a source of financing has prompted the need for a deep and liquid bond market. The government bond market has grown in breadth and depth with regular issuance of benchmark bonds, a broad investor base, diverse and innovative products, and sound market institutions and infrastructure. Establishing a substantial enough issuance volume has contributed to a more reliable yield curve, thus providing a benchmark for the private sector's bond issuance and enhancing liquidity in the secondary bond market trading. Savings bonds, floating-rate bonds, and inflation-linked bonds are issued to broaden the investor base and provide investors with diversified products as well as risk-hedging instruments.

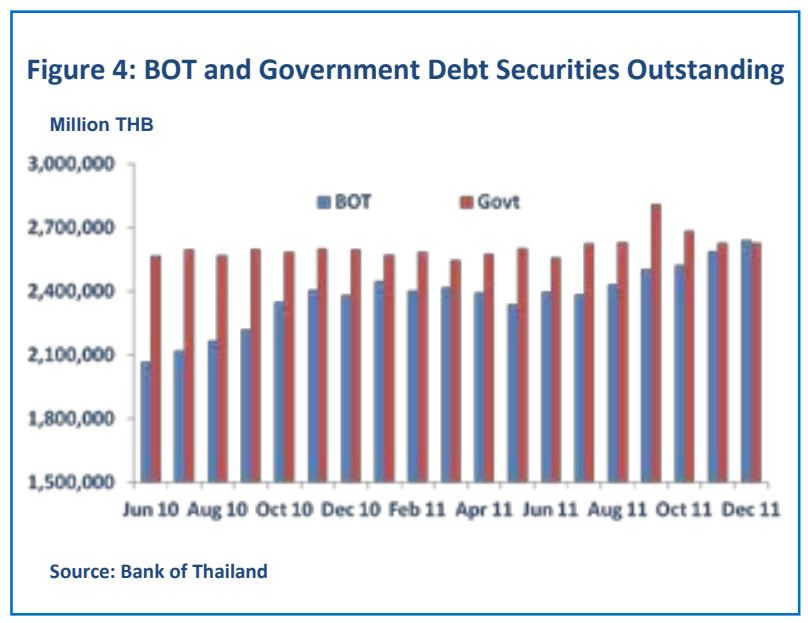

3. The BOT has also become an important issuer in the Thai bond market as its sterilization needs grow. Since 2003, the BOT has issued its own debt paper on a regular basis as another monetary instrument used to absorb excess liquidity in the system. As of end-2011, total outstanding BOT bills and bonds stood at approximately 2.642 trillion baht, compared with 2.627 trillion baht outstanding of government bonds and treasury bills.

4. The BOT coordinates closely with the Public Debt Management Office (PDMO) to ensure the best possible outcome for the bond market as a whole. The presence of two "sovereign" issuers may not be ideal as it could cause market segmentation and make both securities less liquid. To mitigate this potential negative impact, the BOT and the PDMO coordinate closely and continually 
throughout the year, both formally and informally. The PDMO holds quarterly meetings for the debt management committees, in which BOT representatives take part, to discuss and plan the issuance calendar. To avoid competing with each other, the timing and maturities of issuance are carefully designed for both issuers to complement one another. The government primarily issues longer-term benchmark bonds (e.g. 5-, 7- and 10-year maturities) with the longest maturity of 50 years, while the BOT issues its securities with a maximum maturity of 4 years. Their auctions are also held on different days of the week. In addition, the BOT also facilitated the first issuance of government inflation-linked bonds (ILBs) by providing technical support in the calculation of real yields and pricing along with supportive registration system and helped resolve related regulatory issues to ensure its smooth launch.

4.2 Nevertheless, as cross-border capital flows surge, it is critical to strike a balance between promoting market development and ensuring financial stability

1. Foreign participation has enhanced liquidity in the bond market, but large and volatile capital flows have rendered domestic bond markets susceptible to sudden price movements and greater disruption. In the early stage of bond market development, non-resident investors were exempted from withholding tax in an effort to attract foreign investors into the domestic debt market, in order to enhance liquidity. However, volatile global market sentiments have heightened volatility in the domestic bond market and occasionally became the primary factor affecting the yield curve - both in the short and the long end. In October 2010, Thailand reintroduced the withholding tax on non-resident investors, in response to a surge in short-term capital inflows which seemed speculative in nature and caused excessive exchange rate volatility. Thus, the role of foreign investment in the domestic debt market needs to be carefully considered in order to reap its benefit without making the country more vulnerable.

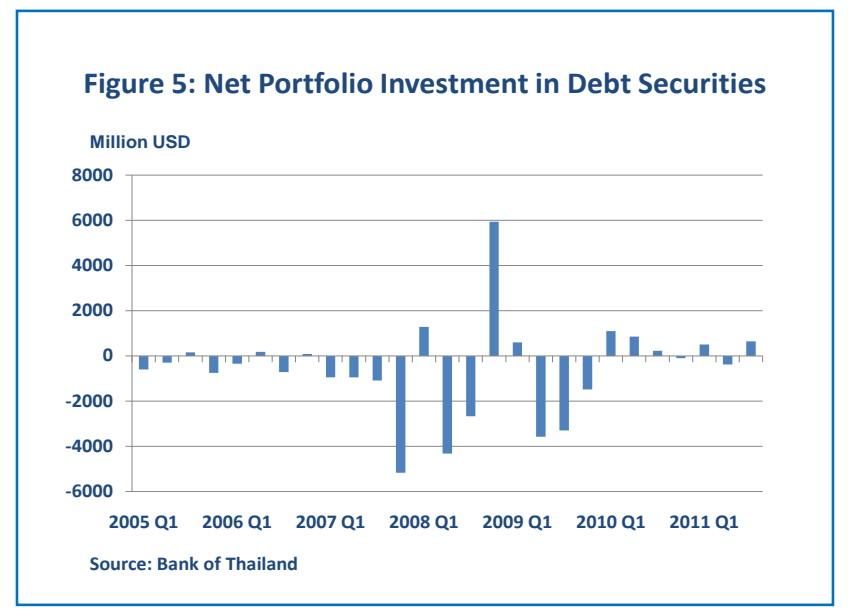

2. The impact of capital flows on bond yields may hinder monetary policy transmission. From time to time, the movement in the short end of the yield curve has misaligned with that of the policy rate due to large capital inflows. As bond yields factor into the pricing behavior of commercial banks and impact retail rates, such misalignment, in effect, may moderate the degree of interest rate pass-through 
from the policy rate to retail rates. ${ }^{3} \mathrm{~A}$ large proportion of the change in long-term yields in Asia over the last decade can be explained by global factors, ${ }^{4}$ which may subject the cost of long-term funding (via the bond market) to global factors rather than domestic financial conditions. This may, consequently, hinder monetary policy transmission.

3 Pongsaparn R, S Wongwaisiriwat, P Chotewattanakul and S Vimolchalao (2011), "Challenges to Monetary Operations in a Small Inflation-Targeting Economy: Living with Foreign Exchange Flows", European Central Bank Workshop on The post-crisis design of the operational framework for the implementation of monetary policy, Frankfurt am Main (October 2011).

4 International Monetary Fund (2011), Regional Economic Outlook: Asia and Pacific (Washington, April). 